\title{
Patrimonio inmaterial de la parroquia Zaruma: Estudio de percepción del potencial turístico y sentido de pertenencia
}

\author{
Intangible heritage of the Zaruma urban parish: \\ Study of the perception of the tourist potential and \\ sense of belonging
}

Arana Salazar, Marlon Universidad Técnica de Machala

(Machala - Ecuador)

Lazo Serrano, Lizette Universidad Técnica de Machala (Machala - Ecuador) llazo@utmachala.edu.ec

Bastidas, María Isabel Universidad Técnica de Machala (Machala - Ecuador)

Lazo Serrano, Arlene Universidad Técnica de Machala (Machala - Ecuador) clazo@utmachala.edu.ec

Revista Cumbres Vol.5 №2

Versión impresa ISSN 1390-9541

Versión electrónica ISSN 1390-3365

http://investigacion.utmachala.edu.ec/revistas/index.php/Cumbres 


\title{
RESUMEN
}

A través del siguiente trabajo de investigación se busca determinar la percepción que posee la población la parroquia urbana de Zaruma de entre 25 a 65 años edad, con relación al potencial turístico y sentido de pertenencia de los bienes patrimoniales inmateriales de la zona; lo cual permitió realizar un estudio de opinión que ayudó a identificar cómo lo perciben, qué valor tiene para ellos actualmente este tipo de patrimonio y como estos están potenciando el turismo en el lugar; para lo cual se procedió a utilizar una metodología cuali-cuantitativa, con la que se aplicaron herramientas de recolección de información como encuestas a la población y entrevistas a funcionarios de entidades públicas a nivel local y regional encargadas de gestión y conservación del patrimonio cultural. Con la obtención de los resultados se pudo concluir que la población urbana de Zaruma no reconoce ni identifica todo su patrimonio inmaterial, ya que muchas de las estrategias aplicadas no están haciendo llegar la información sobre estos bienes inmateriales de manera adecuada y correcta para los ciudadanos.

Palabras clave: Patrimonio Inmaterial, identidad, turismo cultural, patrimonio, Zaruma.

\begin{abstract}
The following research work seeks to determine the perception that the population of the urban parish of Zaruma has between 25 and 65 years old, in relation to the tourist potential and sense of belonging of intangible heritage assets in the area; which allowed for an opinion study that helped to identify how they perceive it, what value this type of heritage has for them at present and how they are promoting tourism in the place; To this end, a qualitative-quantitative methodology was used, with which information gathering tools were applied, such as surveys of the population and interviews with officials of public entities at the local and regional levels responsible for management and conservation of cultural heritage. With the obtaining of the results it was possible to conclude that the urban population of Zaruma does not recognize or identify all its intangible heritage, since many of the applied strategies are not getting the information about these immaterial goods in an adequate and correct way for the citizens.
\end{abstract}

Keywords: Intangible heritage, identity, cultural tourism, heritage, Zaruma.

\section{Cumbres}




\section{INTRODUCCIÓN}

La identidad y cultura son siempre características que ayudan a identificar y reconocer a una población. "Hasta hace sólo unas décadas el patrimonio cultural era visto como un conjunto discreto de bienes materiales con un valor intrínseco y único." (Pedrotta, Tancredi, Mariano, \& Endere, 2013). En la actualidad ese concepto ha evolucionado e incluye a los bienes intangibles:

El patrimonio cultural está conformado por bienes tangibles e intangibles, los cuales se transmiten y difunden de una generación a otra, posibilitando la identificación y la conformación del sentido de pertenencia entre los individuos que conforman una colectividad determinada, en relación con otras realidades sociales. (Congreso Iberoamericano de Patrimonio Cultural, 2016, p.391)

El patrimonio cultural inmaterial (PCI), está vinculado únicamente con bienes intangibles que se transfieren de generación en generación y ayudan a identificar a un individuo o colectivo (Congreso Iberoamericano de Patrimonio Cultural, 2016). En muchas ocasiones los gestos, expresiones o formas de habla suelen ser los primeros nexos que impulsan o despiertan la curiosidad en los turistas e invitan de manera directa a conocer más sobre su historia, leyendas, fiestas, tradiciones, platos típicos entre otros. La UNESCO, en la Convención para la Salvaguardia del Patrimonio Cultural Inmaterial 2003 lo definió como:

Los usos, representaciones, expresiones, conocimientos y técnicas junto con los instrumentos, objetos, artefactos y espacios culturales que les son inherentes, que las comunidades, los grupos y en algunos casos los individuos reconozcan como parte integrante de su patrimonio cultural. El patrimonio cultural inmaterial, que se transmite de generación en generación, es recreado constantemente por las comunidades y grupos en función de su entorno, su interacción con la naturaleza y su historia, infundiendo un sentimiento de identidad y continuidad. (UNESCO, 2003, p. 2)

Debido a que el recurso turístico está determinado por los bienes únicos de un lugar en donde el ser humano interactúa y con los cuales desarrolla múltiples actividades para satisfacer o encantar a los turistas (Martí \& Agramunt, 2014), la actividad turística ha de considerar los efectos inducidos sobre el patrimonio cultural y los elementos, actividades y dinámicas tradicionales de las comunidades locales. El reconocimiento de estos factores locales y el apoyo a su identidad, cultura e intereses, deben ser referentes obligados en la formulación de las estrategias turísticas, especialmente en los países en vías de desarrollo (Conferencia Mundial de Turismo Sostenible, 1995).

Por ello, y según lo expresado por diferentes autores, el turismo se debe considerar como una de las herramientas más importantes para que las comunidades no desaparezcan por la falta de recursos económicos, sino más bien vean en sus raíces históricas y culturales nuevas formas responsables de promocionar, conservar y difundir su patrimonio cultural inmaterial. En el Ecuador, el Instituto Nacional de Patrimonio y Cultura (INPC) con 39 
años de funcionamiento, es la entidad pública encargada de la vigilancia, control técnico e investigación de todo el patrimonio cultural del país, como lo dictaminan los artículos 42, 43, 44 del Cap. 3 de la Ley Orgánica de Cultura. (LOC, 2016). Basándose en los principios de conservación del PCI establecidos por la UNESCO en el 2003, el INPC mantiene registrado 63 bienes intangibles en las siguientes categorías: Artes del espectáculo, Conocimientos y usos relacionados con la naturaleza y el universo, Técnicas artesanales tradicionales, Tradiciones y expresiones orales, Usos sociales, rituales y actos festivos.

El cantón Zaruma ubicado en la provincia de El Oro es considerado como una ciudad patrimonio del Ecuador y que se encuentra en lista de espera para ser decretada como patrimonio cultural de la humanidad de La Organización de las Naciones Unidas para la Educación, la Ciencia y la Cultura (UNESCO). Para cumplir con este objetivo todos los términos relacionados con la apropiación de identidad, historia y costumbres del lugar deben estar fuertemente arraigadas con su diario vivir y así demostrar que la ciudad y sus habitantes se merecen este reconocimiento de carácter mundial.

Por ello este trabajo se planteó la siguiente pregunta investigativa: ¿Cuál es la percepción de la población del centro urbano de Zaruma, respecto al potencial turístico y sentido de pertenencia de los bienes patrimoniales inmateriales de la zona?

Se plantearon los siguientes objetivos:

- Determinar la percepción de la población del centro urbano de Zaruma, respecto al potencial turístico y sentido de pertenencia de los bienes patrimoniales inmateriales de la parroquia urbana.

- Evaluar el conocimiento y valoración de la ciudadanía sobre el patrimonio inmaterial de su ciudad y su potencial turístico.

- Identificar el sentido de pertenencia e identidad de la población local respecto al patrimonio inmaterial.

El lineamiento de esta investigación consiste en determinar qué tanto conocen los habitantes de la parroquia urbana de Zaruma sobre el patrimonio cultural inmaterial que existe en esta zona, cómo lo diferencian, cómo lo valoran y en qué nivel ellos se sienten identificados con éste.

El 'Estudio de opinión del potencial turístico y sentido de pertenencia de los bienes patrimoniales inmateriales de la parroquia urbana Zaruma' consiste en medir qué tan influyente es en su diario vivir y cómo este patrimonio puede convertirse en una fuente económica sustentable, teniendo en cuenta la situación actual que vive una población que en la gran mayoría de su tiempo se ha dedicado a la actividad minera.

\section{MATERIALES Y MÉTODOS}

Para la recopilación de información se utilizó el método cuanti-cualitativo, a través de encuestas realizadas a una muestra representativa de 195 habitantes de 25 a 65 años de la parroquia urbana de Zaruma, cuyo total poblacional es de 4623; con el objetivo de identificar el nivel de percepción en cuanto al

\section{Cumbres}


patrimonio inmaterial.

En la parte cualitativa, se utilizaron entrevistas a los responsables de gestión y control del patrimonio y cultura de instituciones como: Museo $\mathrm{Mu}-$ nicipal de Zaruma, Unidad de promoción y difusión de turismo del GAD Municipal de Zaruma, Unidad de Cultura del GAD de Zaruma, y Coordinación zonal (zona 7) de la Dirección de Cultura y Patrimonio. Con el objetivo de identificar qué gestiones se están desarrollando desde la gobernanza para la conservación del patrimonio cultural.

\section{RESULTADOS}

\section{Encuestas a la población}

De las encuestas que se aplicaron a los habitantes de la parroquia urbana de Zaruma se obtuvieron los siguientes resultados:

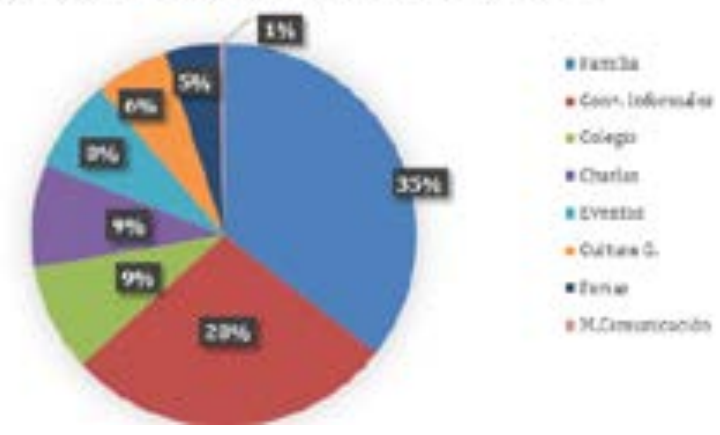

Figura 1. Aprendizaje sobre el Patrimonio Cultural Inmaterial

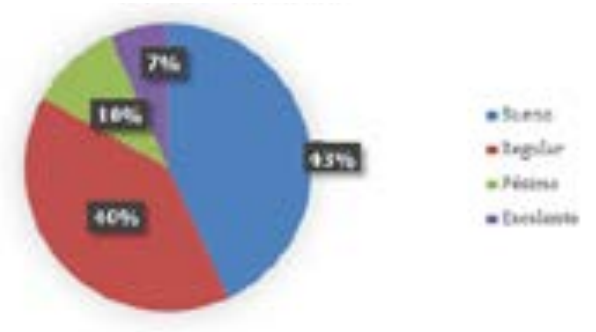

Figura 2. Estado del Patrimonio Cultural Inmaterial de la Parroquia Zaruma

Los bienes patrimoniales inmateriales para ellos representan su identidad como moradores de este sector que se caracteriza por su riqueza histórica y su cultura. La forma más eficaz en la que los ciudadanos recuerdan haber aprendido sobre su identidad y legado cultural ha sido a través de la herencia familiar, ya que es el primer contacto que tienen al nacer los nuevos habitantes de la ciudad, lo que significa que las estrategias de eventos culturales y eventos no están mostrando resultados favorables al hablar sobre la percepción hacia las manifestaciones inmateriales. 
El calificativo que le brindan al estado de patrimonio inmaterial es "bueno" aunque sostienen que se podría mejorar el estado y conocimientos de todas las costumbres, expresiones y tradiciones si realmente las autoridades tomaran en serio la difusión de todo este patrimonio a los habitantes, no solo en eventos y fechas especiales.

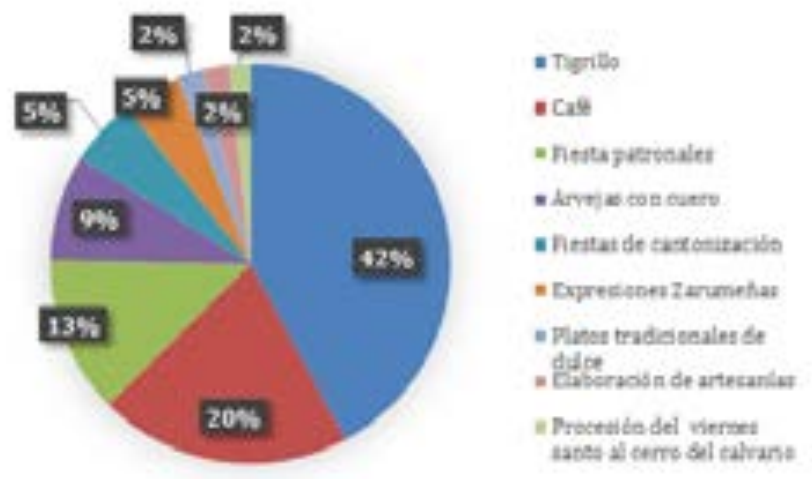

Figura 3. Bienes inmateriales con los que se siente identificado

El bien inmaterial que más conocen y con el que más se sienten identificados es el tigrillo, ya que este plato típico es la insignia gastronómica y uno de los puntos fuertes por el cual la gente visita esta ciudad.

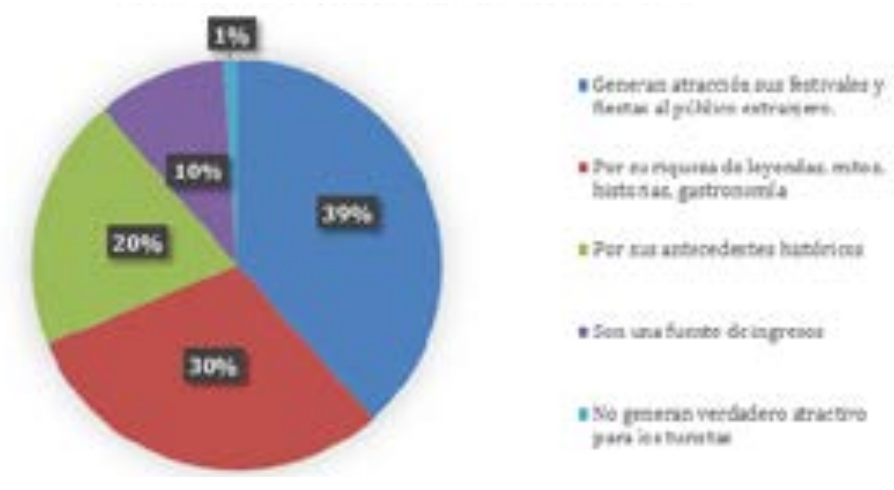

Figura 4. Importancia de los bienes Patrimoniales inmateriales para fomentar el turismo

Para el universo, las festividades generan gran atractivo turístico, e ignoran el resto de bienes como la gastronomía, técnicas artesanales, medicina tradicional que pueden ampliar el margen para que se disfruten más de otros atractivos turísticos y se mejore el sentido pertenencia.

\section{Entrevistas}

En resultado a las entrevistas que se aplicaron a los encargados de las diferentes instituciones públicas responsables del control del patrimonio cultural inmaterial en esta ciudad, se obtuvieron los siguientes resultados:

\section{Cumbres}


Los funcionarios a quienes se les realizó la entrevista a la jefa de la unidad de cultura del GAD, que tiene 20 años en el cargo; al técnico de la unidad de promoción y difusión de turismo del GAD, que tiene 3 años en el cargo; al encargado del museo municipal que lleva 2 años 6 meses y al coordinador zonal (zona 7) de la dirección de cultura y arte, que lleva 3 años en el cargo. Para la conservación del patrimonio inmaterial, se desarrollan eventos, actos y representaciones culturales, casas abiertas; para su difusión se desarrollan charlas con el fin de recuperar la memoria social de la cultura de Zaruma.

La conservación de este patrimonio se realiza a través de la práctica de estos como: juegos tradicionales, momentos culturales, uso de redes sociales para que los turistas tanto los que visitan la ciudad, como los que usan las redes sociales conozcan más sobre la ciudad.

\section{CONCLUSIONES}

El análisis de los resultados de esta investigación permite establecer la relación entre la percepción, valoración y sentido de pertenencia del patrimonio inmaterial que tienen los habitantes de la parroquia urbana de Zaruma. Teniendo en consideración, que, de acuerdo a García (2007), “la valoración del patrimonio está sujeta al uso, vivencias y apropiación que hacen los habitantes en cada generación."; este estudio adquiere significativa importancia para evidenciar potenciales ejes de acción en el ámbito patrimonial y turístico.

En este contexto y de acuerdo a los resultados obtenidos, se puede inferir que la población del centro urbano de Zaruma tiene una percepción significativamente baja de los bienes patrimoniales inmateriales de la zona y por añadidura del potencial turístico de los mismos. Esta cuestión es de gran importancia, considerando que todas las manifestaciones culturales que sean consideradas patrimonio, se reconocen como tal cuando los grupos sociales las hacen propias y las asumen como colectividad (Pástor, 2003), es decir la relación comunidad y patrimonio es condición para que se establezca la identidad y posterior potencialidad de dicho patrimonio.

Este tema lo abordan Mendoza y otros (2008) en el estudio del potencial turístico del patrimonio en una ciudad de México, la penosa realidad de aquellas ciudades que no sólo los visitantes desconocen su patrimonio, sino también la comunidad local; convirtiéndose en una desventaja y condición negativa para el desarrollo y aprovechamiento del potencial turístico, y para contrarrestarla se deberían plantear estrategias de uso social y turístico responsable sin afectar al patrimonio.

En primera instancia, se puede evidenciar que uno de los orígenes de esta percepción, se encuentra en el escaso conocimiento de los bienes patrimoniales inmateriales, reconociendo únicamente nueve de 63 registrados en el Instituto Nacional de Cultura (INPC) y de éstos dos con mayor recordación: el tigrillo y el café; ambos pertenecientes a la subcategoría gastronomía, del catálogo por categorías del INPC. En este sentido Toselli (2019) menciona 
que es relevante mantener un inventario de tractivos turísticos vinculados a los temas patrimoniales, actualizado e integral, esto permitiría tomar decisiones e impulsar acciones como: la identificación de todo el patrimonio cultural sin distinción, difusión del mismo, detectar nuevos atractivos que podrías ser puestos en valor, posibles emprendimientos y espacios culturales como museos o centros de interpretación.

El patrimonio cultural asociado al desarrollo contribuye a crear industrias culturales y a ampliar ámbitos de lo social y lo económico en relación con el fenómeno de patrimonialización de la cultura. La puesta en valor de los bienes patrimoniales, aparte, puede significar beneficios en general y especialmente en los entornos de las culturas locales. Un turismo sostenible contribuye a la conservación del patrimonio, al tiempo que se convierte en vehículo de desarrollo social. (Arévalo, 2010)

Asimismo, esta valoración no se puede decretar ni condicionar, por lo que será necesario ayudar a la gente a interpretar su entorno natural y cultural de tal manera de descubrir el significado y las interrelaciones ecológicas, sociales y culturales existentes entre los componentes presentes en ese entorno y entre ellos y las personas. (García, 2007)

Los resultados indican que no se toma en serio su difusión por parte de las entidades encargadas, además, que la realización de actos o eventos culturales, están pensados para el turista y no para la población local, lo cual desemboca en que los ciudadanos no asistan a estos eventos y esto hace que no haya oportunidad de participar o simplemente pierdan el interés en este tipo de actividades.

La educación patrimonial es un área que abarca varios ámbitos y su desarrollo puede incidir en el cambio de visión en el entorno social, en los derechos implícitos en la conservación y el acceso al patrimonio cultural, el compromiso y el sentido de pertenencia individual o colectivo. En este contexto la educación patrimonial debe ser utilizada como una herramienta de gestión para la creación de enfoques y estrategias didácticas que permitan a la ciudadanía ser parte del patrimonio cultural para lograr una interrelación con los sujetos y la resignificación de los bienes. (García, 2017)

En cuanto al potencial turístico, los zarumeños piensan que las fiestas y festivales son los únicos medios culturales para generar ingresos a través del patrimonio inmaterial.

- A pesar de que conocen que este patrimonio, representa la identidad e historia del zarumeño, se demuestra que no se ha tenido un mayor acercamiento con los otros bienes inmateriales por lo que no se tiene una valoración más familiarizada que afecta únicamente a la ciudad como punto cultural de turismo.

- En su gran mayoría, la población, no conoce su patrimonio inmaterial, no logra sentirse identificado en estos bienes, ya que no se ha creado un sentido de pertenencia entre ellos al ser a través de la familia el método por el cual más se ha aprendido sobre el patrimonio, lo que provoca que no se tengan bien definido e identificados todos los bienes patrimoniales intangibles del centro urbano de Zaruma.

\section{Cumbres}


El patrimonio inmaterial se construye con la constante interacción de todos los actores sociales, el proceso dialéctico por naturaleza genera cambios y como consecuencia son causa de crisis e conflictos de intereses, sin embargo, desde la visión y noción de salvaguardia se pretende ocultar este fenómeno, ya que se lo estudia como un objeto o manifestación paralizado en el tiempo y gestionándolo como tal. (Torres \& Falcerri, 2017)

\section{REFERENCIAS BIBLIOGRÁFICAS}

Álvarez Litben, S. G. \& Litben, S. G. A. (2016). ¿Es posible un patrimonio cultural para el Sumak Kawsay?: un largo camino por recorrer. PASOS Revista de Turismo y Patrimonio Cultural, 14(1), 285-299.

Arévalo, J. M. (2010). El patrimonio como representación colectiva. La intangibilidad de los bienes culturales. Gazeta de Antropología, 1(26). Obtenido de http://hdl.handle.net/10481/6799

Caraballo Perichi, C. (2008). El patrimonio cultural y los nuevos criterios de intervención. La participación de los actores sociales. Revista Palapa.

Carta de Turismo Sostenible (1995). Conferencia Mundial de Turismo Sostenible. Lanzarote, Islas Canarias, España. Disponible en: https://bit.ly/2lw$\mathrm{J} 1 \mathrm{Kk}$

Cerdas González, R. J. (2013). Talleres comunitarios de artes y oficios: una propuesta para el rescate de los patrimonios de los grupos artesanales, el caso del cantón de Pococí. Limón. Costa Rica. InterSedes: Revista de Las Sedes Regionales, XIV(29). Disponible en: https://bit.ly/2kcSbeG

El Comercio. Explotación minera y mala planificación urbana son los dos riesgos de Zaruma. Disponible en: https://bit.ly/2lwHnZa

García, Z. (2017). APRENDIZAJE DIALÓGICO Y APROPIACIÓN DEL PATRIMONIO CULTURAL: Una educación patrimonio sostenida en hombros de gigantes. Revista Teias, 18(48), 83-97. doi:doi.org/10.12957/ teias.2017.25225

Gobierno Municipal de Zaruma. (2009, 2014). Información General de Zaruma. Disponible en: https://bit.ly/2kcZJOB

ICOMOS. (1999). Carta internacional sobre turismo cultural La Gestión del Turismo en los sitios con Patrimonio Significativo. Disponible en: https:// bit.ly/2JRWVlt

Ley Orgánica de Cultura, (Diciembre 30, 2016). Ley Orgánica de Cultura viernes 30 de diciembre de 2016 Sexto Suplemento - Registro Oficial No 913. (E. Nacional, Ed.).

Lo material y lo inmaterial en la construcción de nuestra. (2016) Congreso iberoamericano de patrimonio cultural. Disponible en: https://bit.ly/2ltlfyN

Mendoza, M., José, R., Ruiz, M., Rodríguez, P., Figueroa, E., \& Zapata, V. (2008). Potencial turístico del patrimonio cultural de la ciudad de Texcoco. Teoría y Praxis, 389-402.

Mariano, M., \& Endere, M. \& Mariano, C. (2014). Herramientas metodológicas para la gestión del patrimonio intangible El caso del municipio de 
Olavarría, Buenos Aires, Argentina. Revista Colombiana de Antropología. Disponible en: https://bit.ly/2lKwXF8

Martí, L. C. \& Agramunt, R. A. (2014). Recurso cultural, recurso turístico y producto turístico. ¿Qué creó realmente el plan piloto de dinamización de producto turístico de Xàtiva (Valencia)? Revista Paper. Disponible en: https://bit.ly/2kapQFP

Moliner, M., \& Pérez, C. N. (2015). El empoderamiento patrimonial desde la gestión museística: Museo Palacio Arzobispal y Museo Basílica Catedral de Lima, Perú. Arché. Disponible en: https://bit.ly/2klWtjP

Moliner, B. Lorente, Pérez. Los testigos patrimoniales como recursos precursores de sinergias sociales: El proyecto de cooperación al desarrollo cultural y formativo en Ecuador. Revista. bras. Planej. Desenv., Curitiba, v. 5, n. 2, p. 219-245.

Osorio, J. A. O. (2016). La aventura del turismo; revivificando la cultura a través del turismo y el patrimonio. International Journal of scientific Management and Tourism, 2(2), 285-295.

Pástor, M. (2003). Patrimonio cultural como opción turística. Horizontes Antropológicos, 9(20), 97-115.

Pedrotta, V., Tancredi, M., Mariano, M., \& Endere, y. M. L. (2013). Tejiendo saberes. Patrimonio intangible, identidad y valoración social, Revista Runa, 91, 112.

Rodríguez, Chaves, A., \& Rosales, S. (2016). Turismo y Patrimonio cultural inmaterial: Alternativa de complementariedad para el desarrollo de los territorios rurales. Revista Espiga, Disponible en: https://bit.ly/2lNplBO

Sánchez, R. L. (2015). Perspectivas del turismo cultural. Comercialización de la cultura y fortalecimiento de identidad. Revista Publicando, 2(5), 265-276.

Sistema de información del patrimonio cultural ecuatoriano (SIPCE). Disponible en: https://bit.ly/2lt6yvt

Torres, S., \& Falcerri, L. (2017). Patrimonio inmaterial: tres estudios de caso Ecuador, Colombia, Perú. Antropología Cuadernos de Investigación (18), 76-92.

Toselli, C. (2019). Turismo, patrimonio cultural y desarrollo local. Evaluación del potencial turístico de las aldeas rurales en la provincia de Entre Ríos, Argentina. Pasos, 17(2), 343-361. doi:https://doi.org/10.25145/j.pasos.2019.17.024

Velasco. (2016). El turismo cultural, ámbito privilegiado para la protección del patrimonio cultural inmaterial. Revista Telos. Disponible en: https:// bit.ly/2lt7qAf

UNESCO (2003). Convención para la Salvaguardia del Patrimonio Cultural Inmaterial. París. Disponible en: https://bit.ly/1kFDhCW

UNESCO. (2004). Patrimonio inmaterial. Disponible en: https://bit.ly/2jZdMXS

\section{Cumbres}

